\title{
Angiotensin II-induced Cardiac Fibrosis in the Rat Is Increased by Chronic Inhibition of Nitric Oxide Synthase
}

Jian Hou, Hiroshi Kato, Richard A. Cohen, Aram V. Chobanian, and Peter Brecher

Departments of Biochemistry and the Whitaker Cardiovascular Institute, Boston University School of Medicine,

Boston, Massachusetts 02118

\begin{abstract}
These studies were performed to determine if the effects of angiotensin II infusion on the development of cardiac fibrosis could be modified by the chronic inhibition of nitric oxide synthase activity. $N^{\mathrm{G}}$-nitro-L-arginine-methyl ester (LNAME) was administered to adult Wistar rats in drinking water $(40 \mathrm{mg} / \mathrm{kg}$ per d). Although blood pressure was maintained at hypertensive levels after 2 wk, cardiac hypertrophy or fibrosis did not occur. Angiotensin II, given for $\mathbf{3} \mathbf{d}$ at a dose which induced little or no blood pressure elevation and minimal if any fibrosis, caused significant fibrosis when given to a rat pretreated for 2 wk with L-NAME. This marked fibrosis did not occur if angiotensin II was given shortly after L-NAME treatment was begun or briefly after discontinuation of L-NAME. The fibrosis that occurred with combined treatment was characterized by increased immunodetectable fibronectin, the presence of inflammatory cells within interstitial and perivascular regions, and increased steady state mRNA levels for matrix genes and atrial natriuretic protein. The data indicated a regulatory role for nitric oxide in modulating the angiotensin II-induced cardiac fibrosis and suggest a potentially important autocrine or paracrine role for nitric oxide in fibroblast proliferation. ( $J$. Clin. Invest. 1995. 96:2469-2477.) Key words: hypertrophy • fibronectin • extracellular matrix • hypertension • fibroblasts
\end{abstract}

\section{Introduction}

Myocardial fibrosis is a consequence of remodeling processes initiated by pathophysiological events associated with hypertension, cardiac hypertrophy, and ischemic injury. The renin-angiotensin system is known to influence cardiac function and can induce cardiac fibrosis under different experimental conditions (1-3). In a recent study (4), we used a model in which pressor doses of angiotensin II (ang II) ${ }^{1}$ were infused by osmotic pump

Address correspondence to Peter Brecher, Boston University School of Medicine, 80 East Concord Street, Boston, MA 02118. Phone: 617-6384022; FAX: 617-638-4066.

Received for publication 26 January 1995 and accepted in revised form 11 August 1995.

1. Abbreviations used in this paper: ang II, angiotensin II; ANP, atrial natriuretic peptide; GAPDH, glyceraldehyde 3-phosphate dehydrogenase; L-NAME, $N^{\mathrm{G}}$-nitro-L-arginine methyl ester; PCNA, proliferating cell nuclear antigen.

J. Clin. Invest.

(c) The American Society for Clinical Investigation, Inc.

0021-9738/95/11/2469/09 \$2.00

Volume 96, November 1995, 2469-2477 to rats for periods up to $1 \mathrm{wk}$. Within $3 \mathrm{~d}$, there were major changes in cardiac extracellular matrix gene expression. Fibronectin expression increased in regions associated with both perivascular and interstitial fibrosis and appeared to signal the initial phases of cardiac fibrosis. Additional experiments using antihypertensive drugs were consistent with the possibility that ang II acted directly on cardiac cells. Other studies (5-9) using cultured cardiac fibroblasts and myocytes have provided evidence that ang II receptors are present on these cells and mediate both hypertrophic and hyperplastic responses in vitro.

Nitric oxide (NO) produced by a constitutive form of nitric oxide synthase in vascular endothelial cells is generally considered to have an important role in maintaining vascular tone and blood flow to different organs including the heart, (10) and can influence the function of different cardiac cell types. The presence of both constitutive and inducible forms of nitric oxide synthase have been described in cardiac tissue (11). In vitro studies with cultured cardiac myocytes have suggested a negative inotropic effect of NO (12), but other studies $(13,14)$ have suggested that physiological levels of NO do not exert a major regulatory effect on cardiac contractility, but do alter the inotropic response to beta adrenergic agonists. Hemodynamic studies have shown that inhibition of NO production causes a reduction in cardiac output in several animal models $(15,16)$, and chronic inhibition of nitric oxide synthase activity in intact rats using $N^{\mathrm{G}}$-nitro-L-arginine methyl ester (L-NAME) have led to the interesting observation that cardiac hypertrophy did not occur in most animals despite increased blood pressure (17).

The current study was performed to determine if chronic nitric oxide synthase inhibition in the rat might influence the effects of ang II on the development of cardiac fibrosis. The rationale for these studies is based on the potentially opposing effects of ang II and NO on vascular tone and cellular proliferation, since NO is well established as an important vasodilator and has been suggested to act as an antiproliferative agent both in vitro and in vivo, whereas ang II is considered both as a vasoconstrictor and growth factor. The findings show that in the presence of NO inhibition, the heart is more susceptible to the deleterious effects of ang II, indicating a potentially important interrelationship between ang II and NO under physiological conditions.

\section{Methods}

Materials. Human angiotensin II (acetate salt), L-arginine, and LNAME were purchased from Sigma Chemical Co: (St. Louis, MO), and sodium pentobarbital from Abbott Laboratories (Chicago, IL). Losartan was generously provided by Dupont/Merck (Wilmington, DE). $\left[\alpha-{ }^{32} \mathrm{P}\right] \mathrm{dCTP}$, was obtained from Dupont/NEN Corp. (Boston, MA). Experimental animal models. Male Wistar rats weighing 200-225 grams were purchased from Charles River Breeding Laboratories, Inc., (Wilmington, MA) and allowed $1 \mathrm{wk}$ to adjust to the facilities before 
all experimental protocols. Under standardized conditions, rats were given L-NAME in the drinking water at a dosage of $40 \mathrm{mg} / \mathrm{kg}$ per d. Control rats were given only water. Routine monitoring showed that the animals consumed $\sim 50 \mathrm{ml}$ of drinking water each day whether or not L-NAME was included, and the drinking patterns did not change throughout all treatment protocols. After $14 \mathrm{~d}$, control rats or those given L-NAME were anesthetized and osmotic minipumps from Alza Corp. (Palo Alto, CA) containing ang II dissolved in $0.15 \mathrm{~mol} /$ liter $\mathrm{NaCl}, 1 \mathrm{mmol} /$ liter acetic acid were implanted to deliver drug at a dosage of $0.225 \mathrm{mg} / \mathrm{kg}$ per d. Losartan was given at dosages of 10 or $20 \mathrm{mg} / \mathrm{kg}$ per $\mathrm{d}$ ad lib. via the drinking water with treatment initiated $1 \mathrm{~d}$ before pump implant. L-arginine was given in the drinking water 7 $\mathrm{d}$ before implantation of the pump at a dosage of $4 \mathrm{grams} / \mathrm{kg}$ per $\mathrm{d}$.

Systolic blood pressures were obtained by tail cuff plethysmography. Blood pressure levels were determined before angiotensin II treatment and 4-6 $\mathrm{h}$ before killing. In all experiments, the reported value at each time point is an average of multiple (4-6) recordings. Nembutal was used as surgical anesthesia $(50 \mathrm{mg} / \mathrm{kg})$ and for overdosing ( 0.5 grams/ $\mathrm{kg}$ ) rats. For histochemical studies, cardiectomy was followed by retrograde aortic perfusion with PBS and $10 \%$ formalin. For biochemical analysis, hearts were dissected by removal of the pericardium. Ventricle free walls, septum, and atria were separated from fibrous septum and then washed in cold PBS. Samples were flash frozen in liquid nitrogen for subsequent extraction of RNA or protein.

RNA isolation and Northern blot hybridization. Total RNA from cardiac tissue was extracted using the method of Chomczynski and Sacchi (18) with a 20 -fold volume of guanidinium thiocyanate buffer for the initial homogenization. Northern blot analysis was performed as described (19). Equal loading of RNA was confirmed by visual examination of ribosomal RNA using ethidium bromide staining. cDNA probes were generated using a random prime nucleotide synthesis kit, (Amersham International, Little Chalfont, United Kingdom) and hybridization was performed at $65^{\circ} \mathrm{C}$ for all cDNA probes.

Tissue preparation for histology. Rat hearts were fixed with $10 \%$ formalin and paraffin-embedded using standard procedures. Serial sections were cut at 4- $\mu \mathrm{m}$ thickness, rehydrated, and then used for immunohistochemical analysis. Fibronectin was detected using a rabbit anti-rat antibody (Calbiochem Corp., La Jolla, CA) and detected with a Vectastain Elite ABC kit (Vector Laboratories, Burlingame, CA). Proliferating cell nuclear antigen (PCNA) was measured with PC-10 antibody conjugated to horseradish peroxidase (EPOS system; Dako Corporation, Carpinteria, CA). The antibody to type I collagen was a rabbit antimouse antibody generously provided by Dr. David Salant and was detected with the Vectastain Elite $\mathrm{ABC}$ kit. Detection of monocyte/ macrophages was performed with the ED-1 anti-rat antibody (Biosource International, Camarillo, TX) and detected with the Vectastain ABC-AP kit. For immunohistochemistry, slides were counterstained with Gill's hematoxylin.

$c D N A$. The cDNA probes for fibronectin, type III collagen, glyceraldehyde 3-phosphate dehydrogenase (GAPDH) and pre-pro atrial natriuretic factor (ANP) were identical to those used by us in a previous study (4).

Measurement of aortic cGMP. The general protocol was similar to that described recently (20). Aortic tissue was removed from treated rats, and the thoracic region carefully stripped of adhering adventitia and segmented into four rings, $\sim 5 \mathrm{~mm}$ in length. The rings were preincubated at $37^{\circ} \mathrm{C}$ for $60 \mathrm{~min}$ in a physiological salt solution containing (mmol/liter) $118.3 \mathrm{NaCl}, 4.7 \mathrm{KCl}, 2.5 \mathrm{CaCl}_{2}, 1.2 \mathrm{KH}_{2} \mathrm{PO}_{4}, 1.2$ $\mathrm{MgSO}_{4}, 25.0 \mathrm{NaHCO}_{3}, 5.5$ dextrose, and 0.026 disodium EDTA. The buffer was equilibrated with $95 \% \mathrm{O}_{2} / 5 \% \mathrm{CO}_{2}$ throughout the procedure. After a 30-min incubation, a set of rings from each animal was treated with $\mathrm{L}$-arginine $(1.0 \mathrm{mmol} / \mathrm{liter})$ for an additional $30 \mathrm{~min}$. Rings from each set were rapidly frozen for subsequent analysis of cGMP. Each ring was subsequently homogenized in $1 \mathrm{ml} 6 \%$ trichloroacetic acid and centrifuged at $12,000 \mathrm{~g}$ for $3 \mathrm{~min}$. The supernatant was washed four times with water-saturated ethyl ether, frozen, and lyophilized. The dried residue was resuspended in $1 \mathrm{ml} 0.05 \mathrm{~mol} /$ liter sodium acetate buffer and aliquots were assayed using a commercial kit obtained from Biomedical Technologies, Inc. (Stoughton, MA).

Statistical analysis. All values are expressed as mean \pm SEM. Values for body and heart weights, blood pressures, densitometric quantitation, and subsequent calculations based on these measurements, were compared using a one-way ANOVA. Subsequent comparisons were performed using a two-tailed, unpaired Student $t$ test.

\section{Results}

In preliminary studies, animals pretreated with L-NAME for 14 $\mathrm{d}$ were given ang II by osmotic minipump, using a dose $(0.75$ $\mathrm{mg} / \mathrm{kg}$ per d) that we had reported previously to increase blood pressure and produce cardiac fibrosis within $3 \mathrm{~d}$ in otherwise untreated rats (4). The animals pretreated with L-NAME became extremely ill after implantation of the pump containing ang II, and most died within $3 \mathrm{~d}$. In subsequent experiments, a lower dose of ang II was used $(0.225 \mathrm{mg} / \mathrm{kg}$ per $\mathrm{d})$, which did not increase blood pressure to hypertensive levels, nor did it produce cardiac fibrosis if administered to untreated rats. Fig. $1 A$ is a representative Northern blot analysis of RNA taken from the ventricles of rats treated with ang II and L-NAME, either alone or in combination. Each lane contains $15 \mu \mathrm{g}$ of total RNA from the left ventricle of an individual rat. For animals given only L-NAME for a total of $17 \mathrm{~d}$, there were no changes in steady state mRNA levels for fibronectin or for a fibrillar form of collagen, both of which are good markers for fibrosis, nor was there a major change in ANP, which is probably the most reliable and sensitive marker for a hypertrophic change in the phenotype of ventricular myocytes. Similarly, 3 $\mathrm{d}$ treatment with a low dose of ang II did not change extracellular matrix genes, although it did have a slight effect on ANP expression. In contrast, treatment with both L-NAME and ang II, the latter given for the last $3 \mathrm{~d}$, caused a major increase in the expression of all the marker genes studied. Densitometric analysis of the changes in steady state mRNA levels caused by the different treatments is summarized in Fig. $1 \mathrm{~B}$. Fibronectin mRNA increased most dramatically in the 3-d treatment period when ang II was given to L-NAME-treated rats, the average increase being $>50$-fold that of control levels, although each of the marker genes were obviously affected by the combined treatment. Treatment with the low dose of ang II alone did affect ANP expression slightly, with a statistically significant increase of $75 \%(P<0.01)$.

Several experimental interventions were studied in this LNAME-ang II model. Losartan administered concurrently with ang II suppressed the biochemical changes (Fig. $2 \mathrm{~A}$ ), although steady state mRNA levels did not return completely to control levels. Coadministration of L-arginine during the latter half of the 17-d protocol with L-NAME and ang II also reversed the effects of the combined treatment on fibronectin and, to a lesser extent, ANP expression. Fig. $2 B$ shows a representative Northern blot comparing the effects of duration of L-NAME treatment before administration of ang II. If L-NAME pretreatment were for only $2 \mathrm{~d}$, (rather than $14 \mathrm{~d}$ ), and then ang II was given for $3 \mathrm{~d}$ in the continued presence of L-NAME, there was no appreciable response to ang II. Furthermore, despite persistent hypertension, there were no appreciable changes in steady state mRNA levels for fibronectin or collagen relative to control values in ventricles from animals given L-NAME alone for times $>17 \mathrm{~d}$ (Fig. $2 \mathrm{~B}$ ).

Fig. 3 summarizes densitometric analysis of the mRNA lev- 


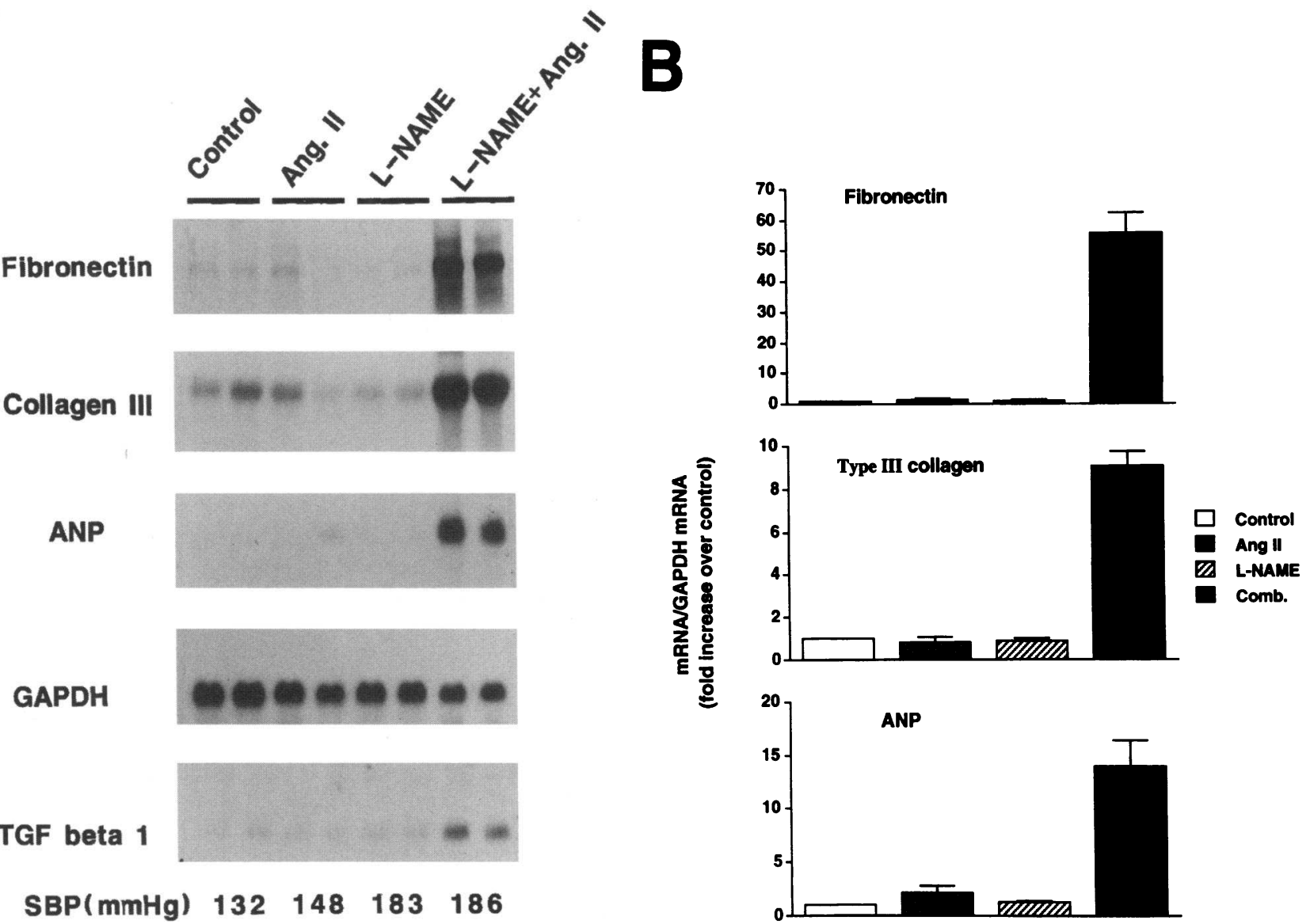

Figure 1. Effect of L-NAME and ang II treatment on left ventricular steady state mRNA levels for selected genes. (A) Representative Northern blot showing effects of $18 \mathrm{~d}$ treatment with L-NAME, $3 \mathrm{~d}$ treatment with ang II, or combined treatment giving ang II during the last $3 \mathrm{~d}$ of L-NAME treatment ( see text for details). Each lane contains $15 \mu \mathrm{g}$ total RNA from the left ventricle of a rat from the designated treatment group. The average systolic blood pressure $(S B P)$ for a larger group of animals treated similarly is shown at the bottom of the figure. $(B)$ Bar graph summarizing densitometric analysis of data from rats in each treatment group. Data are expressed as a ratio of the designated gene to GAPDH relative to the control, which was given an arbitrary ratio of 1 . Each group consists of at least five animals, and error bars refer to the standard error of the mean.

els for the marker genes using the different protocols. When losartan was given at a relatively high dose of $20 \mathrm{mg} / \mathrm{kg}$ per d there was a greater suppression of gene expression than was observed with $10 \mathrm{mg} / \mathrm{kg}$ per d, suggesting that in this model, inhibition was not accomplished at doses that would normally suppress the effects of higher amounts of ang II in the absence of L-NAME treatment. The effects of discontinuing L-NAME after $14 \mathrm{~d}$ of treatment before giving ang II also are shown in Fig. 3 and indicate that the sensitization of the heart to ang II by L-NAME was reversible. When ang II was given for a 3-d period only $1 \mathrm{~d}$ after discontinuing L-NAME, the response to ang II was diminished considerably with respect to fibronectin expression, although ANP mRNA levels did remain high. The effect of discontinuing L-NAME treatment was more obvious when ang II was given $6 \mathrm{~d}$ after removing L-NAME from the drinking water, and all marker genes were close to control levels (data not shown). Prolonged L-NAME treatment for between 5-7 wk, in the absence of ang II treatment produced only slight changes relative to controls.

Table I summarizes the changes in blood pressure, body, and heart weight in the different treatment groups. Also shown is the change of body weight during the last $3 \mathrm{~d}$ of the specific treatment. Ang II alone, at the dose given, increased blood pressure significantly, although not to hypertensive levels. When ang II was given alone for $3 \mathrm{~d}$, rats experienced only slight changes in body weight and no significant change in heart weight. After $14 \mathrm{~d}$ of L-NAME treatment, animals were clearly hypertensive with systolic blood pressure averaging $183 \mathrm{mmHg}$, but there were no changes in heart weight/body weight ratios. When ang II was given to L-NAME-treated rats between days 14-17, blood pressure remained elevated, but did not increase further over the levels found in rats given L-NAME alone. The animals showed a marked loss in body weight ( $>50$ grams in $3 \mathrm{~d})$, even though fluid intake was unchanged during this time. Heart weight was not affected but the heart weight/body weight ratio increased significantly. Losartan treatment, at either dose, did not affect blood pressure, but prevented the marked loss of body weight and therefore reduced heart weight/body weight ratios. L-arginine treatment did not affect blood pressure significantly in the time intervals studied, but partially prevented the loss of body weight seen with animals given the standard combined treatment. When ang II was given for a 3-d period 


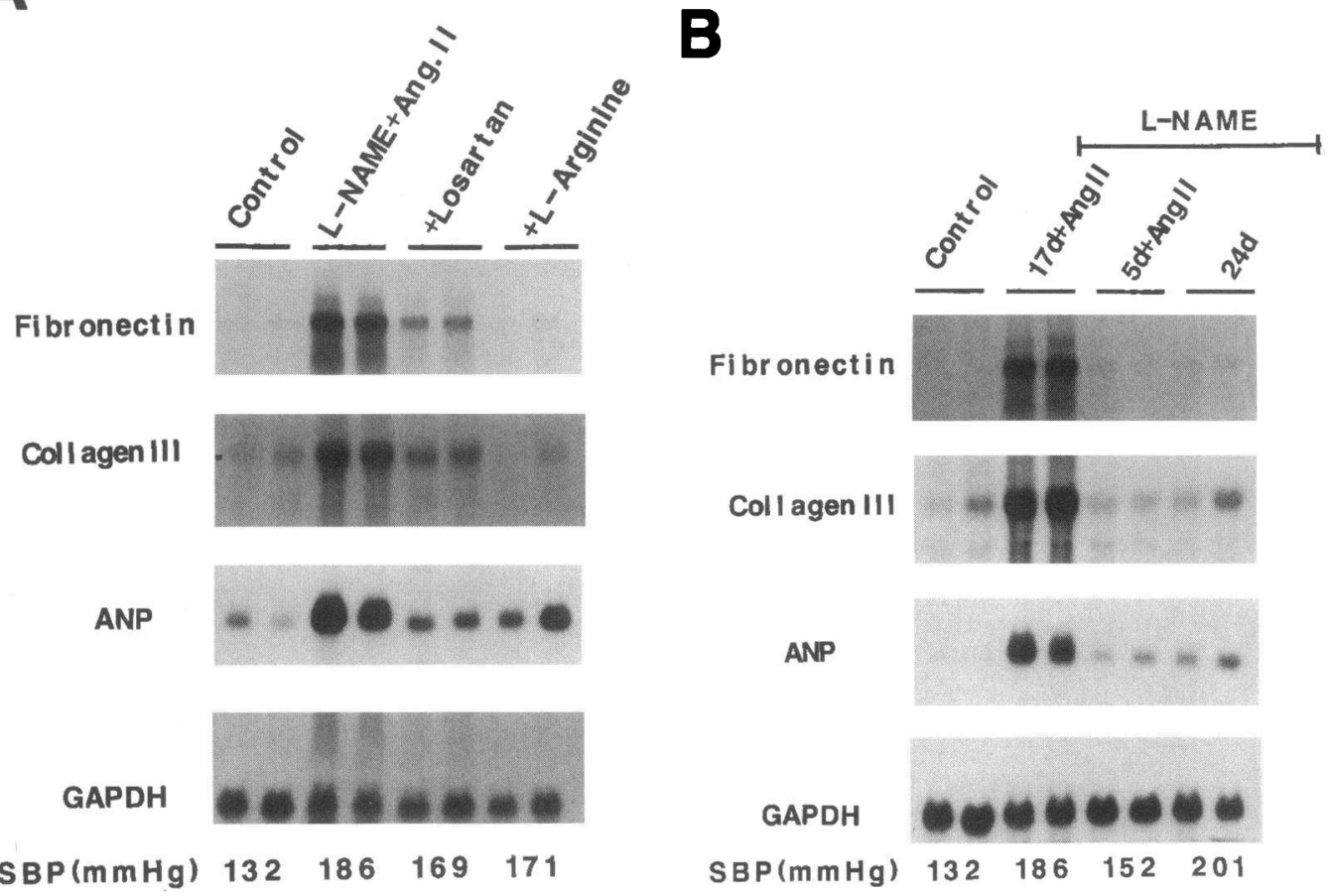

Figure 2. Effects of losartan and L-arginine or duration of L-NAME treatment on ventricular gene expression in rats treated with L-NAME and ang II. $(A)$ Representative Northern blot showing steady state mRNA levels for fibronectin, collagen, ANP, and GAPDH in control rats, rats given the combined treatment with L-NAME and ang II, and rats given either losartan $(10 \mathrm{mg} / \mathrm{kg}$ per d) or L-arginine $(4$ grams $/ \mathrm{kg}$ per d) during the combined treatment with L-NAME and ang II. Each lane contains $15 \mu \mathrm{g}$ total RNA from the ventricle of a separate rat. (B) Representative Northern blot showing effect of duration of L-NAME treatment on the cardiac response to ang II infusion. Rats were given L-NAME for 17 or $5 \mathrm{~d}$, with ang II infusions administered within the last $3 \mathrm{~d}$ of treatment. Control rats were given neither L-NAME nor ang II. Also shown are results from rats given L-NAME only for $24 \mathrm{~d}$. Average values for systolic blood pressure are shown below.

after discontinuation of L-NAME, blood pressure and heart weight were similar to the standardized combined treatment, but the body weight loss normally seen during ang II treatment was attenuated considerably if there was a 6-d lapse between L-NAME and ang II administration. L-NAME administration for 5-7 wk resulted in normal weight gain and caused no change in heart weight/body weight ratio relative to age-matched control animals, yet blood pressure was increased after 1 wk and persisted at hypertensive levels throughout the 7-wk period.

Experiments were performed to assess the influence of LNAME treatment on nitric oxide production. These studies consisted of the in vitro measurement of cGMP levels in aortic rings taken from animals treated in vivo with L-NAME (Fig. 4). There was a significant reduction in cGMP levels between rings obtained from control rats and those taken from animals treated with L-NAME for 5 or $18 \mathrm{~d}$, with or without a 3-d treatment with ang II. In contrast, if L-arginine was given for the latter $10 \mathrm{~d}$ of an 18-d treatment with L-NAME, aortic cGMP levels were not different from control levels. Addition of an excess of L-arginine in vitro to the aortic rings increased cGMP levels, and by inference, NO production, in all cases except for in vivo $\mathrm{L}$-arginine treatment. These data are consistent with $\mathrm{L}$ NAME functioning in vivo to inhibit NO production and the subsequent production of cGMP, and this effect being normalized when L-arginine was given in vivo chronically.

Representative micrographs of left ventricular tissue from control rats and those given combined treatment with L-NAME and ang II are shown in Fig. 5. Fig. $5 A$ is a hematoxylin and eosin-stained section from a control rat not given either ang II or L-NAME. There was no evidence of fibrosis throughout either the left or right ventricle, and the sections looked very similar to those obtained from rats treated either with ang II only or L-NAME only. Fig. $5 C$ shows an adjacent region which was stained using an antibody to fibronectin. There was no indication of immunodetectable protein in this section although in other sections that included arterioles, fibronectin could be seen associated with and on the adventitial side of the vascular smooth muscle. In striking contrast, when animals were given both ang II and L-NAME, extensive fibrosis was present throughout both ventricles, and in perivascular and interstitial areas. Fig. $5 B$ shows a representative region of interstitial fibrosis. Fig. $5 \mathrm{D}$ demonstrates considerable amounts of immunodetectable fibronectin throughout this fibrotic region.

Fig. 5, $F$ and $H$ depicts a fibrotic region from a rat treated with both ang II plus L-NAME, where an antibody directed towards macrophages (Fig. $5 F$ ) or an adjacent section treated with an antibody to proliferative cell nuclear antigen, (PCNA), a cyclin which is expressed in the nucleus of proliferating cells (Fig. $5 \mathrm{H}$ ). Macrophages, stained red, were clearly present within the fibrotic region indicating the presence of an inflammatory response. PCNA-positive cells were numerous within the fibrotic regions. Throughout many sections, fibroblasts appeared to be the predominant cell type showing PCNA-detectable signal, although a small percentage of macrophages within the fibrotic areas also were PCNA-positive. Occasionally, endothelial cells, vascular smooth muscle cells, and rarely, myocytes, 


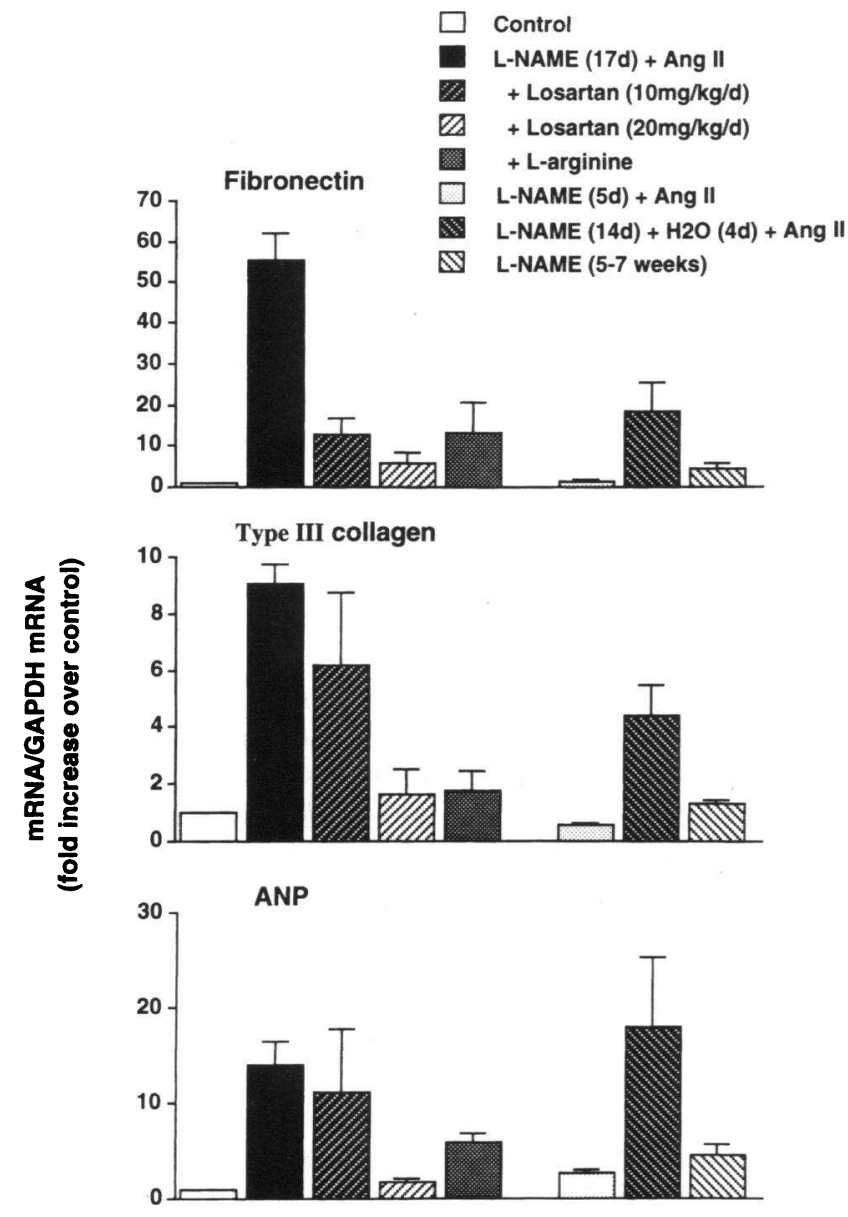

Figure 3. Bar graph summarizing densitometric analysis of mRNA levels in ventricular tissue from different treatment groups. Animals given L-NAME alone for between 5-7 wk were pooled to obtain the data shown in the bar graph on the far right of the figure. Each group contains data from five to nine animals. Data are expressed as a ratio of the designated gene to GAPDH relative to the control, which was given an arbitrary ratio of 1 . Error bars refer to the standard error. also were detectable with the PCNA antibody. When comparable studies were done on tissue from control animals, (Fig. 5, $E$ and $G$ ), there was almost no evidence of macrophage infiltration or PCNA-positive cells, respectively. Animals treated with either ang II or L-NAME alone did have cells that were positive for the macrophage antibody, but these cells were found rarely and were distributed within regions that appeared free of myocyte damage or fibrosis. PCNA-positive cells also were not prevalent in cardiac tissue from animals given either ang II or L-NAME alone. Similarly, animals given losartan or L-arginine also showed little evidence of fibrosis, with only occasional indications of mild perivascular fibrosis (data not shown).

To further document the presence of fibrosis in the hearts of treated rats, Fig. 6 shows representative data using Masson's trichrome staining or a specific antibody directed against collagen type I. The fibrotic regions are shown in Fig. 5, $B$ and $D$ for trichrome staining and collagen, respectively. The blue color characteristic of collagen after Masson's trichrome staining was obvious in all areas of fibrosis (Fig. $5 B$ ) and collagen type I was clearly present in the fibrotic region as indicated by the antibody (Fig. $5 D$ ). Sections from untreated rats, when stained similarly (Fig. 5, $A$ and $C$ ) reflect the marked change induced by combined treatment with ang II and L-NAME.

\section{Discussion}

This study documented a striking interrelationship between nitric oxide synthase inhibition and ang II administration on cardiac tissue. Chronic blockade of nitric oxide production produced a condition where the heart became extremely sensitive to the fibrotic effects of low doses of ang II. This effect, which was associated with myocyte hypertrophy and the presence of inflammatory cells, did not appear to be dependent solely on the elevated blood pressure associated with chronic treatment with L-NAME, since fibrosis or hypertrophy did not occur when rats were treated chronically with L-NAME alone. Furthermore, administration of L-arginine modulated the response to ang II despite being ineffective in lowering blood pressure. The fibrotic response was produced rapidly and was extensive when both ang II and L-NAME were given together, and this exaggerated response presumably would not occur if a normal balance existed between nitric oxide and ang II within cardiac tissue.

Table I. Effect of Drug Treatment on Blood Pressure, Heart Weight, and Body Weight

\begin{tabular}{lccccr}
\hline \multicolumn{1}{c}{$\begin{array}{c}\text { Treatment } \\
\text { groups }\end{array}$} & $\begin{array}{c}\text { No. of } \\
\text { animals }\end{array}$ & $\begin{array}{c}\text { Systolic blood } \\
\text { pressure }\end{array}$ & $\begin{array}{c}\text { Heart } \\
\text { weight }\end{array}$ & $\begin{array}{c}\text { Heart weight } \\
\text { body weight }\end{array}$ & $\begin{array}{c}\text { Change in } \\
\text { body weight* }\end{array}$ \\
& & $m m H g$ & grams & $\times 1,000$ & grams \\
Control (17 d) & 8 & $132 \pm 2$ & $1.13 \pm .04$ & $2.86 \pm 0.1$ & $16.2 \pm 4.4$ \\
L-NAME (17 d) & 6 & $183 \pm 9$ & $1.12 \pm .03$ & $2.77 \pm 0.1$ & $15.6 \pm 5.2$ \\
Ang II (3 d) & 7 & $148 \pm 10$ & $1.05 \pm .05$ & $3.04 \pm 0.1$ & $-2.3 \pm 3.1$ \\
L-NAME + angII & 10 & $186 \pm 5$ & $1.17 \pm .03$ & $3.52 \pm 0.1$ & $-53.4 \pm 6.4$ \\
L-NAME + ang II + losartan (10 mg/kg per d) & 6 & $182 \pm 7$ & $1.15 \pm .05$ & $2.80 \pm 0.1$ & $-4.7 \pm 1.6$ \\
L-NAME + ang II + losartan (20 mg/kg per d) & 6 & $169 \pm 3$ & $1.08 \pm .05$ & $2.72 \pm 0.1$ & $19.8 \pm 5.1$ \\
L-NAME + ang II + L-arginine (4 grams/kg per d) & 6 & $172 \pm 7$ & $1.05 \pm .03$ & $2.74 \pm 0.1$ & $-32.0 \pm 8.3$ \\
L-NAME (5 d) + ang II (3 d) & 6 & $152 \pm 8$ & $0.94 \pm .01$ & $3.16 \pm 0.1$ & $-8.4 \pm 5.6$ \\
L-NAME (14 d) + no treatment (1 d) + ang II (3 d) & 6 & $182 \pm 8$ & $1.13 \pm .04$ & $3.11 \pm 0.1$ & $-36.3 \pm 8.3$ \\
L-NAME (5-7 wk) & 9 & $201 \pm 6$ & $1.30 \pm .05$ & $3.12 \pm 0.1$ & $6.6 \pm 4.1$
\end{tabular}

All data are expressed as mean \pm standard error. ${ }^{*}$ Change in body weight that occurred the last $3 \mathrm{~d}$ of treatment. 


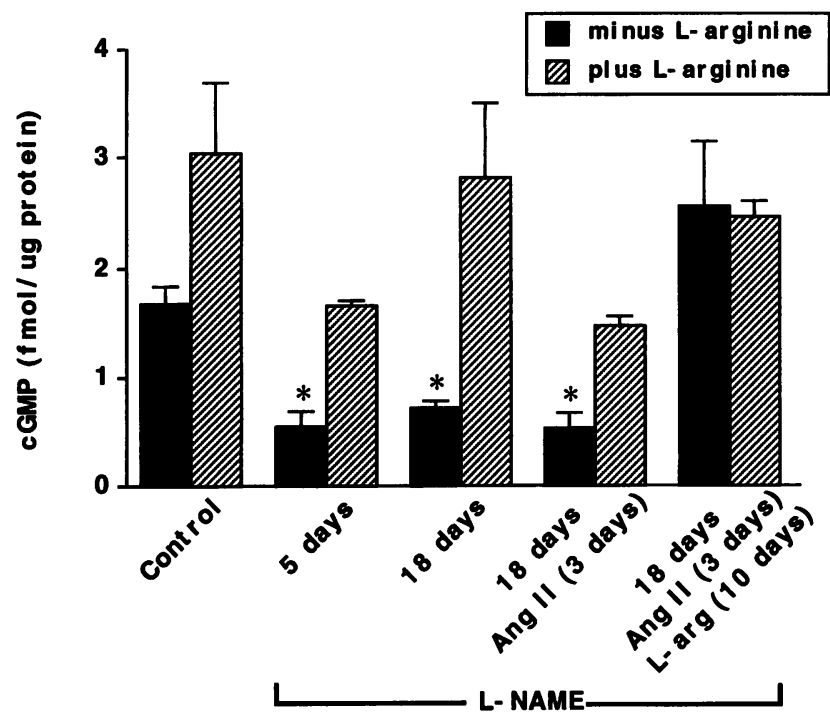

Figure 4. Effects of L-NAME treatment in vivo on the formation of cGMP by aortic rings in vitro. Aortic rings were prepared from different groups of rats after treatment in vivo with L-NAME. The rings were preequilibrated with buffer alone for $60 \mathrm{~min}$ or preequilibrated in the presence of $\mathrm{L}$-arginine for the last $30 \mathrm{~min}$ of the 60 -min preincubation. Individual rings were then frozen for subsequent analysis of cGMP. The treatment groups included: controls (no treatment); 5- or 18-d treatment with L-NAME; combined treatment with L-NAME and ang II; and combined treatment with L-NAME and ang II, including L-arginine for the last $10 \mathrm{~d}$ of the 18-d treatment period. Data are represented as the mean \pm SE for five separate animals in each group. ${ }^{*}$ Significant difference from the control group $(P<0.01)$.

The most dramatic biochemical response we observed was the increase in fibronectin mRNA. The 60 -fold increase in fibronectin mRNA was considerably greater than the increase in cardiac fibronectin mRNA we previously reported using ang II alone at a pressor dose to initiate fibrosis (4). The changes were also greater than were shown previously by us in cardiac tissue from an ischemic rabbit model (21), or in other hypertensive rat models (19). The histochemical data shown in this study indicate that the observed increase in immunodetectable fibronectin was also localized in the fibrotic regions. We (4) and others (22) had previously used in situ hybridization to localize these changes to regions of fibroblast proliferation and showed that fibronectin expression increased before changes in collagen expression, a finding consistent with other models of wound healing. The amount of ang II we used to produce extensive cardiac fibrosis in the L-NAME-treated rats was insufficient to cause similar changes in rats not given L-NAME, suggesting a synergistic effect between L-NAME and ang II on the development of cardiac fibrosis. Ventricular myocytes were also affected by combination drug treatment as reflected by increased ANP expression.

Despite the consistent blood pressure increase that occurred after $\sim 1 \mathrm{wk}$ of L-NAME treatment, we found no indication of increased ventricular weight or heart weight/body weight ratio; only a slight indication of increased ventricular ANP expression, which has been used as a reliable index of myocyte hypertrophy; and no indication of cardiac fibrosis. Arnal et al. (17) showed that after $4 \mathrm{wk}$ of treatment with varying dosages of L-NAME, rats did not develop cardiac hypertrophy despite established hypertension. This unusual cardiac response in hypertensive rats was studied further (23) using longer treatment periods of up to 2 mo of L-NAME administration. In that study, a subset of treated rats $(\sim 25 \%)$ that did develop cardiac hypertrophy also had elevated plasma renin activity and increased cardiac angiotensin converting enzyme activity, responses attributed to possible renal damage. Those results implied that increased activity of the renin-angiotensin system during chronic inhibition of NO production might be a factor in the development of cardiac hypertrophy.

Interrelationships between the renin-angiotensin system and NO have been studied by several groups with conflicting results. Treatment of rats with nitric oxide synthase inhibitors have been shown to increase $(24,25)$ or decrease $(26,27)$ plasma renin activity. Furthermore, angiotensin receptor blockade was shown to prevent the hypertension caused by chronic NO blockade in some studies $(27,28)$, but other studies have indicated that inhibitors of ang II formation or action did not influence the hypertension in rats chronically treated with LNAME (29). In the kidney, the importance of NO in modulating renal hemodynamics is well established, and several studies have emphasized important interrelationships between NO and ang II. It was shown that NO is a physiological antagonist of ang II at both the glomerular and tubular level, suggesting that such interactions could be an important factor in regulating basal renal function $(30,31)$. When rats were given $N^{\mathrm{G}}$-monomethyl-L-arginine after receiving a pressor dose of ang II, renal hemodynamics were impaired, whereas in normotensive animals or in other hypertensive models, the arginine analog did not affect renal hemodynamics (32).

Our findings show an increased sensitivity of the heart to ang II after NO blockade and suggest a tissue-specific response, since the synergistic effect was not related to systemic blood pressure changes. A recent study (33) has compared the hemodynamic responses of different tissues in the rat to chronic LNAME treatment and found that despite the decreased cardiac output, there was little change in coronary blood flow or vascular resistance, in contrast to major changes in both parameters in the kidney, liver, spleen, and several other organs. Thus, chronic L-NAME treatment clearly suggested an important role for NO in modulating long-term regulation of blood pressure, but the different regional effects seen, particularly for heart and brain, did suggest that other NO-independent mechanisms also have an important role in the chronic model.

The efficacy of the chronic L-NAME and arginine treatment to modulate vascular NO synthesis was determined using the production of aortic cGMP as a functional criterion. Previous studies had shown that rats given L-NAME for several weeks led to a markedly decreased production of aortic cGMP (17). We also found a reduction of aortic cGMP in rats given LNAME for either 5 or $18 \mathrm{~d}$, despite the distinctive differences in blood pressure elevation or response to ang II between those two treatment periods. This dissociation between blood pressure changes and vascular response to L-NAME is consistent with earlier studies showing that chronic L-NAME treatment in rabbits caused an attenuated response in vitro to acetylcholine, despite the fact that the dose of L-NAME administered in vivo did not cause hypertension (20). Basal levels of aortic cGMP were not altered by including ang II in the treatment protocol with L-NAME, whereas chronic treatment with L-arginine did normalize the aortic levels of cGMP. Thus, our data indicating that L-arginine can reverse the inhibition of NO synthase in the aorta by L-NAME are consistent with the ability of L-arginine 

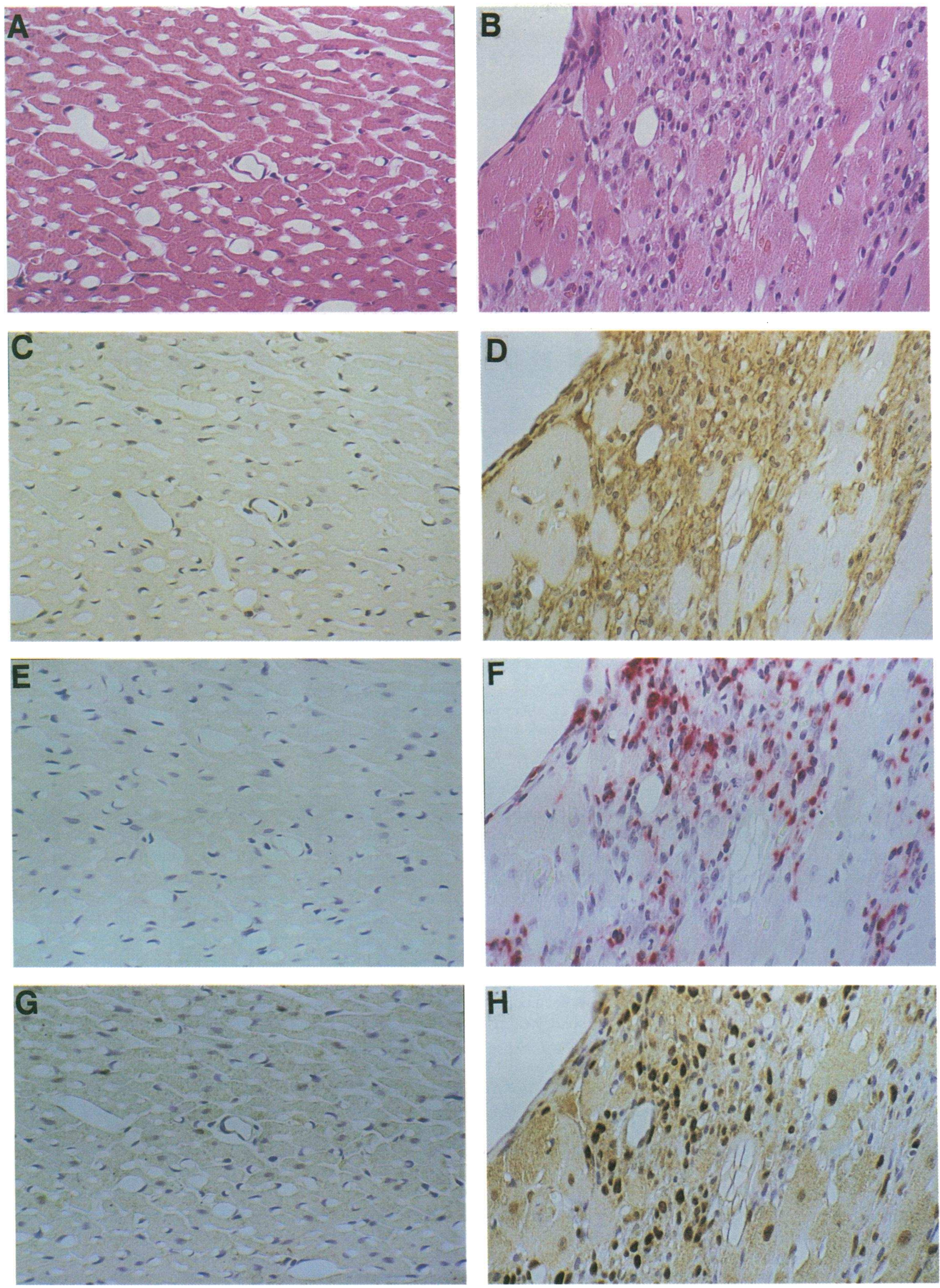

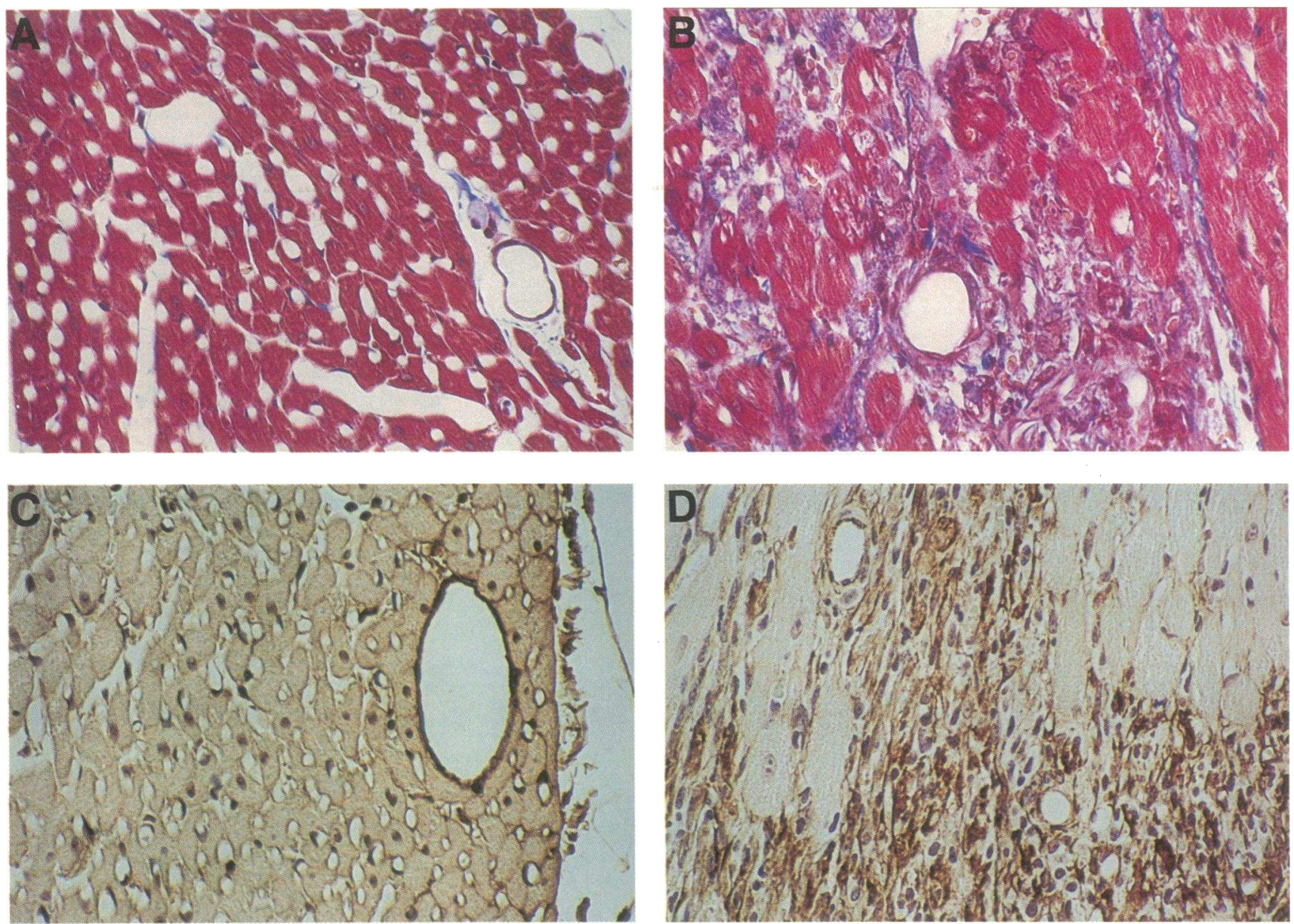

Figure 6. Representative photomicrographs of left ventricular tissue showing fibrosis in rats treated with both L-NAME and ang II. $A$ and $C$ are from control rats stained either with Masson's trichrome $(A)$ or immunodetection of collagen type $\mathrm{I}(B) . B$ and $D$ are regions of fibrosis from rats treated with both L-NAME and ang II as evidenced by Masson's trichrome staining $(B)$ and immunodetection of collagen type I $(D)$. All sections are shown at a magnification of 125 .

to suppress the cardiac fibrotic response via an effect on NO, although these changes were dissociated from blood pressure, which remained elevated during L-arginine treatment. It may be that the unique effects of L-arginine on different vascular beds may be related to the distribution of arginine or the analogs when given in vivo since the transport system for L-arginine in vascular smooth muscle was recently characterized and suggested to be a potential factor in regions of vascular injury (34).

The infiltration of leukocytes in fibrotic regions of the hearts that we found were analogous to other observations documenting the presence of both macrophages and $\mathrm{T}$ lymphocytes in fibrotic regions of ischemic rat hearts (35). Constitutive production of NO prevents the association of leukocytes with vascular endothelial cells (36). Since L-NAME treatment should favor leukocyte attachment to endothelium, perhaps by causing selective induction of adhesion proteins, it is possible that when combined with ang II, which can both directly affect endothelial cells and indirectly promote vasoconstriction, there may be enhanced infiltration of leukocytes into the heart. NO donors have been shown to reduce adhesion of neutrophils to isolated coronary arteries from postischemic cat myocardium (37) and to ablate the ischemia reperfusion-induced inflammatory response in the mesenteric microcirculation of the rat (38). The selective effects of $\mathrm{L}$-arginine that we and others have observed may be due in part to an influence on the NO-mediated changes on leukocyte attachment. The complex cellular responses to LNAME and ang II could be due to a combination of effects on different cardiac cell types. Regulation of the inflammatory response, perhaps in combination with direct effects of ang II on myocytes and interstitial fibroblasts, may explain the severity of the cardiac response to ang II and chronic L-NAME treatment, and point to the potential importance of nitric oxide in regulating the autocrine and paracrine events that lead to cardiac fibrosis.

Figure 5. Representative photomicrographs comparing control ventricular tissue to that from a rat treated with both L-NAME and ang II. ( $A$, $C$, $E$, and $G$ adjacent sections from a control rat heart. $B, D, F$, and $H$ ) adjacent sections from a fibrotic region of a rat treated with both L-NAME and ang II. $A$ and $B$ are stained with hematoxylin and eosin; $C$ and $D$ show immunodetectable fibronectin; $E$ and $F$ show immunodetection of macrophages; $G$ and $H$ show immunodetection of PCNA-positive cells. All sections are shown at a magnification of 125 . 


\section{Acknowledgments}

Ms. Susan Hope provided excellent technical support for the care and treatment of the animals. The authors thank Dr. Joseph Loscalzo for helpful discussions during the preparation and editing of this manuscript. This work was supported by National Institutes of Health Grant HL47124.

\section{References}

1. Weber, K. T. 1994. The what, why and how of hypertensive heart disease. J. Hum. Hypertens. 8:665-675.

2. Bader, M., J. Wagner, M. Lee, and D. Ganten. 1994. The role of the reninangiotensin system in cardiovascular disease. Hypertens. Res. 17:1-16.

3. Baker, K. M., G. W. Booz, and D. E. Dostal. 1992. Cardiac actions of angiotensin II. Role of an intracardiac renin-angiotensin system. Annu. Rev. Physiol. 54:224-241.

4. Crawford, D., A. V. Chobanian, and P. Brecher. 1994. Angiotensin II induces fibronectin expression associated with cardiac fibrosis in the rat. Circ. Res. 74:727-739.

5. Sadoshima, J., and S. Izumo. 1993. Molecular characterization of angiotensin II-induced hypertrophy of cardiac myocytes and hyperplasia of cardiac fibroblasts. Critical role of the AT1 receptor subtype. Circ. Res. 73:413-423.

6. Crabos, M., M. Roth, A. W. A. Hahn, and P. Erne. 1994. Characterization of angiotensin II receptors in cultured adult rat cardiac fibroblasts. J. Clin. Invest. 93:2372-2378.

7. Matsubara, H., M. Kanasaki, S. Muransawa, Y. Tsukaguchi, Y. Nio, and M. Inada. 1994. Differential gene expression and regulation of angiotensin II receptor subtypes in rat cardiac fibroblasts and cardiomyocytes in culture. J. Clin. Invest. 93:1592-1601.

8. Sechi, L. A., C. A. Griffin, E. F. Grady, J. E. Kalinyak, and M. Schambelan. 1992. Characterization of angiotensin II receptor subtypes in rat heart. Circ. Res. 71:1482-1489.

9. Meggs, L. G., J. Coupet, H. Huang, W. Cheng, P. Li, J. M. Capasso, C. J. Homcy, and P. Anversa. 1993. Regulation of angiotensin II receptors on ventricular myocytes after myocardial infarction in rats. Circ. Res. 72:1149-1162.

10. Lowenstein, C. J., and S. H. Snyder. 1992. Nitric oxide, a novel biologic messenger. Cell. 70:705-707.

11. Schulz, R., E. Nava, and S. Moncada. 1992. Induction and potential biological relevance of a $\mathrm{Ca}^{++}$-independent nitric oxide synthase in the myocardium. Br. J. Pharmacol. 105:575-580.

12. Finkel, M. S., C. V. Oddis, T. D. Jacob, S. C. Watkins, B. G. Haltter, and R. L. Simmons. 1992. Negative inotropic effects of cytokines on the heart mediated by nitric oxide. Science. (Wash. DC) 257:387-389.

13. Weyrich, A. S., X.-L. Ma, M. Buerke, T. Murohara, V. E. Armstead A. M. Lefer, J. M. Nicolas, A. P. Thomas, D. J. Lefer, and J. Vinten-Johansen 1994. Physiological concentrations of nitric oxide do not elicit an acute negative inotropic effect in unstimulated cardiac muscle. Circ. Res. 75:692-700.

14. Balligand, J. L., D. Ungureanu, R. A. Kelly, L. Kobzik, D. Pimental, T. Michel, and T. W. Smith. 1993. Abnormal contractile function due to induction of nitric oxide synthesis in rat cardiac myocytes follows exposure to activated macrophage-conditioned medium. J. Clin. Invest. 91:2314-2319.

15. Gardiner, S. M., A. M. Compton, P. A. Kemp, and T. Bennett. 1990 Regional and cardiac hemodynamic effects of $\mathrm{N}^{\mathrm{G}}$-nitro-L-arginine methyl ester in conscious, Long Evans rats. Br. J. Pharmacol. 101:625-631.

16. Klabunde, R. E., N. D. Kimber, J. E. Kuk, M. C. Helgren, and U. Forstermann. 1992. $\mathrm{N}^{\mathrm{G}}$-Methyl-L-arginine decreases contractility, cGMP and cAMP in isoproterenol-stimulated rat hearts in vitro. Eur. J. Pharmacol. 223:1-7.

17. Arnal, J. F., L. Warin, and J. B. Michel. 1992. Determinants of aortic cyclic guanosine monophosphate in hypertension induced by chronic inhibition of nitric oxide synthase. J. Clin. Invest. 90:647-652.
18. Chomczynski, P., and N. Sacchi. 1987. Single-step method of RNA isolation by acid guanidinium thiocyanate-phenol-chloroform. Anal. Biochem. 162:156-159.

19. Mamuya, W. S., and P. Brecher. 1992. Fibronectin expression in the normal and hypertrophic rat heart. J. Clin. Invest. 89:392-401.

20. Cayatte, A. J., J. J. Palacino, K. Horten, and R. A. Cohen. 1994. Chronic inhibition of nitric oxide production accelerates neointima formation and impairs endothelial function in hypercholesterolemic rabbits. Arterioscler. Thromb. 14:753-759.

21. Knowlton, A. A., C. M. Connely, G. M. Romo, W. F. Mamuya, C. S. Apstein, and P. Brecher. 1992. Rapid expression of fibronectin in the rabbit heart afer myocardial infarction with and without reperfusion. J. Clin. Invest. 89:10601068.

22. Samuel, J. L., A. Barrieux, S. Dufour, I. Dubus, F. Contard, V. Koteliasky, F. Farhadian, F. Marotte, J-P. Thiery, and L. Rappaport. 1991. Accumulation of fetal fibronectin mRNAs during the development of rat cardiac hypertrophy induced by pressure overload. J. Clin. Invest. 88:1737-1746.

23. Amal, J. F., A. I. E. Amrani, G. Chatellier, J. Menard, and J. B. Michel. 1993. Cardiac weight in hypertension induced by nitric oxide synthase blockade. Hypertension (Dallas) 22:380-387.

24. Ribeirio, O. M., E. Antunes, G. D. Nucci, S. M. Lovisolo, and R. Zatz. 1992. Chronic inhibition of nitric oxide synthesis. A new model of arterial hypertension. Hypertension (Dallas). 20:298-303.

25. Hu, L., R. D. Manning, Jr, and M. W. Brands. 1994. Long-term cardiovascular role of nitric oxide in conscious rats. Hypertension (Dallas). 23:185-194.

26. Dananberg, J., R. S. Sider, and R. J. Grekin. 1993. Sustained hypertension induced by orally administered nitro-L-arginine. Hypertension (Dallas). 21:359363.

27. Pollock, D. M., J. S. Polakowski, B. J. Divish, and T. J. Opgenorth. 1993. Angiotensin blockade reverses hypertension during long-term nitric oxide synthase inhibition. Hypertension (Dallas). 21:660-666.

28. Bank, N., H. S. Aynedjian, and G. A. Khan. 1994. Mechanism of vasoconstriction induced by chronic inhibition of nitric oxide in rats. Hypertension. (Dal las). 24:322-328.

29. Qiu C., K. Engels, and C. Baylis. 1994. Angiotensin II and $\alpha 1$-adrenergic tone in chronic nitric oxide blockade-induced hypertension. Am. J. Physiol. 266:(Regulatory Integrative Comp. Physiol. 35):R1470-R1476.

30. Nicola, L. D., R. C. Blantz, and F. B. Gabbai. 1992. Nitric oxide and angiotensin II. Glomerular and tubular interaction in the rat. J. Clin. Invest. $89: 1248-1256$

31. Sigmon, D. H., and W. H. Beriwaltes. 1994. Nitric oxide influences blood folow distribution in renovascular hypertension. Hypertension (Dallas). 23(Suppl. I):I34-I39.

32. King, A. J., P. Mercer, J. L. Troy, and B. M. Brenner. 1991. Endotheliumderived relaxing factor and the vascular reply to systemic hyertension. J. Am Soc. Nephrol. 2:1072-1077.

33. Huang, M., R. D. Manning, Jr., M. H. LeBlanc, and R. L. Hester. 1995 Overall hemodynamic studies after the chronic inhibition of endothelial-derived nitric oxide in rats. Am. J. Hypertens. 8:358-364.

34. Durante, W., L. Liso, and S. I. Schafer. 1995. Differential regulation of L-arginine transport and inducible NOS in cultured vascular smooth muscle cells. Am. J. Physiol. 268(Heart Circ. Physiol. 37):H1158-H1164.

35. Hinglais, N., D. Heudes, A. Nicoletti, C. Mandet, M. Laurent, J. Bariety, and J.-B. Michel. 1994. Colocalization of myocardial fibrosis and inflammatory cells in rats. Lab. Invest. 70:286-294.

36. Kubes, P., M. Suzuki, and D. N. Granger. 1991. Nitric oxide: an endogenous modulator of leukocyte adhesion. Proc. Natl. Acad. Sci. USA. 88:46514655 .

37. Ma, X. L., A. S. Weyrich, D. J. Lefer, and A. M. Lefer. 1993. Diminished basal nitric oxide release after myocardial ischemia and reperfusion promotes neutrophil adherence to coronary endothelium. Circ. Res. 72:403-412.

38. Kurose, I., R. Wolf, M. B. Grisham, and D. N. Granger. 1994. Modulation of ischemia/reperfusion-induced microvascular dysfunction by nitric oxide. Circ. Res. 74:376-382. 